The Role of Mesothelin Expression in Serous Ovarian Carcinoma: Impact on the Diagnosis, Prognosis, and Therapeutic Target.

Giovanna Giordano (a), Elena Ferioli (a), Alessandro Tafuni (a).

a) Department of Medicine and Surgery, Pathology Unit, University of Parma, (Italy).

Correspondence: Prof Giovanna GIORDANO

Department of Medicine and Surgery, Pathology Unit, University of Parma,

Viale A. Gramsci, 14

43126 Parma, (Italy)

E-mail address: giovanna.giordano@unipr.it

\title{
Simple Summary
}

Ovarian cancer is the most lethal gynaecological malignancy, and serous carcinoma is the most common subtype. The lack of symptoms and sensitive diagnostic tests in the early stage of development may explain why the diagnosis often occurs late when the neoplasm has already spread outside the pelvis. Currently, the standard treatment of ovarian carcinomas requires cytoreductive surgery followed by platinum-based systematic chemotherapy, which does not reduce recurrences or mortality. Despite intense efforts to develop novel therapies that involve the use of new chemotherapeutic agents, such as anti-angiogenesis agents and poly (ADP-ribose) polymerase inhibitors that improve patient outcomes, the five-year survival for this malignancy still remains low. Therefore, it is important to identify new targetable molecules for early diagnosis, disease monitoring, and treatment or early diagnosis, disease monitoring, and treatment of this malignancy.

The aim of this review is to discuss the role of mesothelin in serous ovarian carcinomas, focusing on its diagnostic, prognostic, and therapeutic perspectives.

\footnotetext{
Abstract

Mesothelin is a protein that is expressed in the mesothelial cell lining in the pleura, peritoneum, and pericardium. The gene of mesothelin encodes a precursor protein that is processed to yield mesothelin, which is attached to the cell membrane by a glycophosphatidylinositol linkage and a shred fragment named the
} 
megakaryocytic-potentiating factor. The biological functions of this substance in normal cells are still unknown. Experimental studies on knockout mice suggest that this substance does not play an important role in development and reproduction.

In contrast, it has been observed that mesothelin is produced in abnormal amounts in several malignant neoplasms, such as mesotheliomas and pancreatic adenocarcinomas.

Given that mesothelin is overexpressed in many solid tumours and has antigenic properties, this molecule could be considered a tumour marker or an antigenic target for many malignancies. Many molecular studies also have demonstrated that mesothelin is overexpressed in serous ovarian carcinomas and may bind to ovarian cancer antigen Ca-125, favouring the spread of the tumour in the abdominal cavity.

Here, we discuss the current knowledge of mesothelin and focus on its role in clinical and pathological diagnoses as well as its impact on the prognosis in serous ovarian carcinomas.

We also briefly discuss the latest progress of mesothelin-targeting therapies for this aggressive and lethal neoplasm.

Keywords: mesothelin; ovarian carcinoma; biomarker; mesothelin-targeting therapy

\section{Introduction}

Mesothelin (MSLN) is a glycoprotein that is located on the mesothelial lining of the body cavities and in many neoplasms [1]. It is anchored at the cell membrane by a glycosylphosphatidylinositol linkage. The mesothelin gene was first cloned by Chang and Pastan [1], and it encodes a precursor protein that is processed to yield a $40 \mathrm{kDa}$ mesothelin protein and a $31 \mathrm{kDa}$ soluble fragment. The soluble human fragment, named the megakaryocyte-potentiating factor (MPF), was reported to have a megakaryocyte-potentiating activity in mouse bone marrow [2].

In normal tissue, the physiological/biological function of MSLN is still uncertain. Studies in molecular biology have demonstrated that a lack of MSLN in an MSLN knockout mouse model did not affect development, growth, or reproduction [3].

Conversely, MSLN is considered to be involved in several mechanisms of cancer pathogenesis. In 
ovarian carcinomas, it was demonstrated that binding with the partner MUC16 (CA125) could play a role in cell adhesion, facilitating intraperitoneal ovarian cancer metastasis [4-6].

There is evidence that mesothelin can be used as a new cancer biomarker [7] and as a target molecule for gene therapy [8].

Here, we discuss the current knowledge of MSLN, focusing on its role in clinical and pathological diagnoses as well as its impact on the prognosis in serous ovarian carcinomas. We also briefly discuss the latest progress of mesothelin-targeting therapies for this aggressive and lethal neoplasm. 


\section{Materials and Methods}

\section{Search strategy}

We conducted a review of the current literature in accordance with the Preferred Reporting Items for Systematic Reviews and Meta-Analyses Statement PRISMA [9] to report the current knowledge of MSLN in normal tissue and in serous ovarian carcinomas, focusing on its role in diagnosis, prognosis, and therapy. The aim of this review was to report on the latest progress of mesothelin-targeting therapies in this neoplasm.

The medical subject heading terms used for the search in PubMed and Scopus were 'mesothelin' and 'ovarian carcinomas', as well as 'serous carcinoma', 'diagnosis', and 'therapy'.

The systematic review process was performed independently by two authors (E.F. and A.T.) and checked by another (G.G.).

\section{$\underline{\text { Inclusion/exclusion criteria }}$}

Articles considered were published from 1994 to 2021 (June).

The duplicates, e.g., articles that were not written in the English language and those evidently not relevant to the topic based on the title and a revision of the abstract, were excluded from the review. All works describing the MSLN expression and therapies in non-ovarian carcinomas were also excluded from our analysis.

\section{$\underline{\text { Data extraction }}$}

We selected studies that focused on the role of MSLN in clinical and pathological diagnoses as well as its impact on the prognosis in serous ovarian carcinomas and data for MSLN-targeting therapies in ovarian carcinomas, especially the serous subtype.

\section{Results}

The number of records identified through PubMed and Scopus was, respectively, 220 and 160.

Records after duplicated papers were removed amounted to 90 .

Records screened based on title and Abstract were 220.

We excluded 5 articles that were not written in English, 23 studies with a few cases $(<40)$ and 113 not relevant to the topic. Thus, we considered in the paper a total of 79 articles, and their full texts were read.

We also searched for and considered 5 other useful articles present in the bibliography of those already evaluated. 
Analysis of these results has enabled us to report studies on mesothelin as a cancer biomarker for the diagnosis and prognosis of ovarian carcinomas in sera and in other fluids of patients suffering from this severe and lethal neoplasm.

We have also been able to report studies in which the value of MSLN is reported in other diagnostic methods, such as radioimmunoimaging, in immunohistochemical and PCR analysis. Moreover, we reported and discussed papers on mesothelin as a therapeutic target.

\section{Mesothelin as a New Cancer Biomarker for the Diagnosis and Prognosis of Ovarian Carcinomas}

Among gynaecological neoplasms, ovarian carcinomas have the highest mortality because the diagnosis of this malignancy is often late, when the neoplasm is already in an advanced stage of development.

The early detection of this neoplasm is difficult due to the absence of physical symptoms and a lack of sensitive screening methods [10].

\section{$\underline{\text { Mesothelin as a Serological Biomarker }}$}

Cancer antigen 125 (CA125) is currently the most common serological biomarker used for the diagnosis and management of patients with epithelial ovarian/fallopian tube or primary serous peritoneal cancers. Many studies suggest that CA125 can also be expressed at high levels in other types of cancers, such as breast cancer $[11,12]$, mesotheliomas $[13,14]$, non-Hodgkin's lymphoma $[15,16]$, and leukaemia [17], as well as leiomyomas and leiomyosarcomas with a gastrointestinal origin [18]. CA125 was also found to be elevated in the sera of patients with benign conditions, such as cirrhosis, ovarian cysts, endometriosis, pregnancy, congestive heart failure, and musculoskeletal inflammatory disorders [19].

Only half the patients with early stage ovarian carcinomas had elevated CA125 levels [20].

Thus, the sensitivity and specificity of CA125 for the detection of early stage ovarian carcinomas are unfortunately low [21]. Therefore, it is extremely important to identify new molecules for the early diagnosis and disease monitoring of this lethal neoplasm.

Concerning the use of MSLN as a biomarker for the diagnosis of ovarian carcinomas, a significant amount of data in the literature suggests that this substance is expressed in different subtypes of ovarian carcinomas, especially serous [22]. A splice variant of soluble mesothelin, named the soluble megakaryocyte-potentiating factor (SMRP), was found in the sera of patients with ovarian carcinomas [23]. 
6

Studies have reported that SMRP serum was significantly higher in ovarian carcinomas than in benign ovarian lesions and healthy subjects. It was also observed that serum SMRP levels were related to FIGO pathological staging (International Federation of Gynecology and Obstetrics system) and grading of the neoplasms, demonstrating that high serum levels of mesothelin may be indicative of tumour progression and poor survival [24-26].

\section{Mesothelin as a Biomarker in Other Fluids}

Okla et al. observed that peritoneal fluid mesothelin levels did not differ significantly in patients with benign and malignant ovarian epithelial neoplasms. They also did not observe any differences in peritoneal fluid MSLN levels in different FIGO stages and histological types of neoplasms.

Thus, in contrast to the serum levels of MSLN, low levels of MSLN in the peritoneal fluid were not associated with a better prognosis [25].

Studies in the literature have reported that MSLN can also be detected in the urine samples of patients affected by ovarian carcinomas [27-30].

In particular, Badgwell et al. observed, for the first time, that the urinary levels of MSLN could be considered to have a greater sensitivity than the serum levels in the early stages of ovarian carcinomas [27]. Similarly, Hellstrom et al. demonstrated that, in women with a pelvic mass, assaying urine for human epididymis protein 4 (HE4) or mesothelin may detect early ovarian carcinomas more often than assaying the serum [28].

In their study, Hollevoet $\mathrm{K}$ et al. demonstrated that mesothelin levels in the urine depended on an impaired glomerular and tubular function, which could influence the interpretation of the mesothelin measurements and cause false-positive results [30]. Wu et al. considered SMRP serum to be a promising marker for the diagnosis and monitoring of ovarian carcinomas, especially in combination with CA125, showing a sensitivity of $98.4 \%$ and specificity of $88.4 \%$ [24].

\section{Mesothelin as a Biomarker in Radioimmunoimaging}

As mesothelin is a membrane antigen overexpressed in a variety of solid neoplasms, including ovarian carcinomas, there are many studies in the literature that prove that analyses of radioimmunoimaging can be used for the non-invasive detection of mesothelin-overexpressing tumours [31-36]. 
Radioimmunoimaging is a type of molecular nuclear medicine imaging that applies specific antibodies of tumour-specific antigens labelled with radionuclides for imaging [37]. Thus, this molecular imaging allows the assessment of the tumour uptake and distribution in the primary and secondary tumour sites as well as the response to therapy. Different anti-mesothelin antibodies have been used in animal models.

In several studies, anti-mesothelin antibodies were used, and these could be detected by fluorescence imaging or magnetic resonance [32,33]. For detection by positron emission tomography (PET), other authors have demonstrated in ovarian models that 89Zr-labelled antibodies could be used to target MSLN, an antibody-drug conjugate (ADC) that can provide information regarding both the organ distribution and drug dosing [33-36].

\section{Mesothelin Detection in Neoplastic Tissue}

In diagnostic pathology, the immunohistochemical expression of MSLN, in several instances, is a useful marker to distinguish between primary and metastatic ovarian carcinomas. In their paper, Kanner et al. demonstrated that MSLN expression could assist in differentiating Müllerian serous carcinomas from metastatic breast carcinomas (particularly those with a papillary morphology) and documented that none of the breast carcinomas was stained for mesothelin [38].

Ordóñez demonstrated that the carcinomas that most frequently exhibited a strong MSLN reactivity were non-mucinous carcinomas of the ovary; however, they observed that this marker was also expressed in other non-mucinous carcinomas, such as clear-cell carcinomas of the ovary, endodermal sinus tumours, or renal cell carcinomas, as well as clear-cell type and transitional-cell carcinomas of the ovary [22]. Weidemann et al., to identify tumours that might benefit from targeted cancer therapies, observed that the highest prevalence of MSLN positivity was present in ovarian carcinomas (serous 97\%) by the analysis of tissue microarrays for the MSLN expression of 122 different tumour types. Conversely, MSLN was rare in the cancers of the breast, kidney, thyroid gland, soft tissues, and prostate [39].

The immunohistochemical expression of MSLN in the neoplastic section of serous ovarian carcinomas was also investigated to establish its impact on the prognosis.

The literature suggests limited and conflicting immunohistochemical data regarding MSLN expression and the prognostic impact on ovarian cancers.

According to the study of Chang et al., the immunohistochemical MSLN expression was related to 
the survival outcomes in patients with ovarian carcinomas. They observed that the neoplasms with a high expression of mesothelin showed a statistically worse prognosis than those with a low immunoreactivity [40].

Similarly, Yildiz et al. observed that a high expression of MSLN in advanced serous ovarian cancers was associated with a poor prognosis and with worse platinum sensitivity in the advanced stage [41]. Cheng et al. observed that a high MSLN expression, investigated by a molecular study using real-time quantitative reverse transcription-polymerase chain reaction (PCR), was associated with chemoresistance and poor survival in ovarian carcinomas [42].

In contrast, Yen et al., separating neoplasms with diffuse immunoreactivity from neoplasms with focal positivity, observed that a diffused MSLN expression correlated with prolonged patient survival in serous ovarian carcinomas [43]. According to these authors, this finding could indicate that immune response to mesothelin-expressing ovarian carcinoma cells may result in a reduction of tumour load and contribute to a patient's prolonged overall survival. Conversely, neoplasms with focal MSLN expression can progress, as neoplastic cells cannot be detected by the immune system and continue to progress.

To validate immunohistochemical results, in eight frozen representative cases, Yen et al., using reverse transcriptase-PCR, observed that the PCR product of mesothelin was strongly representative in tumours with diffuse mesothelin immunoreactivity (4+ and 3+ positivity) (FIGS 1a and b), but it was scarcely detectable in negative tumours (score: 0).

The results of Yen et al. were not in accordance with those of other studies, in which a high expression of MSLN was associated with poor survival in other malignant epithelial neoplasms, such as lung adenocarcinomas and pancreatic ductal adenocarcinomas [44, 45].

The conflicting data on MSLN expression and its prognostic impact on patients with ovarian carcinomas may be due to many factors, such as the different antibodies, protocols, and criteria used to evaluate the immunoreactivity. Magalhaes et al., by immunohistochemical analysis, demonstrated that MSLN expression in patients with high-grade serous carcinomas did not predict the clinical outcome but correlated with the CD11c+ positive-immune infiltrate in neoplasms. The MSLN expression also significantly correlated with $\mathrm{CD} 11 \mathrm{c}+$ in the metastatic sites and in the perivascular areas of the primary neoplasm. Thus, they concluded that these data could also have an important impact on the outcome of immune-related therapies [46]. 


\section{Mesothelin as a therapeutic target}

Currently, ovarian cancer treatment consists of surgical tumour debulking complemented by taxaneand platinum-based chemotherapy [47], occasionally associated with Avastin (bevacizumab, an anti-vascular endothelial growth factor therapy) [48]. In advanced or recurrent diseases, in patients with a BRCA mutation, maintenance therapy with a poly adenosine diphosphate (ADP-ribose) polymerase (PARP) inhibitor treatment represented an effective treatment option [49].

However, radical treatment regimens and multiple chemotherapeutic treatments do not reduce the recurrences of the disease or the death of the patients.

Given that MSLN is over-expressed in many solid tumours and has antigenic properties, this molecule could be considered to be the antigenic target for immunotherapeutic strategies in ovarian carcinomas. The main immunotherapeutic strategies using different therapeutic agents include antimesothelin immunotoxin SS1P, MORAb-009 (chimeric anti-mesothelin mAb) and anti-mesothelin antibody-drug conjugate (BAY-94 9343). Chimeric antigen receptor T cell (CAR T) therapy and vaccines were also evaluated.

In Figure 2, the main immunotherapeutic strategies for ovarian cancer are summarized (FIG. 2).

\section{$\underline{\text { Anti-Mesothelin Immunotoxin SS1P }}$}

SS1P is an anti-MSLN immunotoxin, which was obtained from immunized mice fused to a truncated form of pseudomonas exotoxin A (PE38) (FIG 2A). SS1P binding to MSLN formed a complex that was internalized by endocytosis and PE, translocated in cytosol and killed cells catalyzing protein synthesis, thus initiating programmed cell death [50]. Studies in vitro have demonstrated the cytotoxic effect of SS1P on the neoplastic cells of patients affected by ovarian carcinomas [51]. In a phase I clinical trial (ClinicalTrials.gov Indentifier: NCT00066651), patients with ovarian carcinomas presented with stable disease. The side effects of treatment are dose-related and include capillary leak syndrome and pleuritis due to SS1P binding to normal mesothelial cells and inflammation. The association with prednisone reduces the risk of toxicity, allowing increased dosage [52]. Moreover, in line with cases of mesothelioma, SS1P could be used in combination with chemotherapy to obtain a major response [53]. However, as observed in treatments for mesotheliomas, it must be kept in mind that the efficacy of SS1P is limited by anti-drug antibody formation. 
Thus, SS1P is being administrated in association with pentostatin and cyclophosphamide, which are lymphocyte-depleting drugs that allow patients to receive multiple cycles of treatments [54].

\section{MORAb-009 (Chimeric Anti-Mesothelin mAb)}

MORAb-009 (chimeric anti-mesothelin mAb), also named amatuximab, represents the heavy and light chain variable regions of a mouse anti-mesothelin single-chain Fv grafted onto a human IgG1 and $\mathrm{k}$ constant region (FIG 2B). MORAb-009 has a high affinity with mesothelin, and, in a preclinical evaluation, it was demonstrated that it could inhibit the adhesion between the cell lines expressing mesothelin and MUC 16 (Ca 125), as well as cause cell-mediated cytotoxicity on mesothelin-bearing tumour cells [55].

In clinical trials, it has been observed that patients treated with MORAb-009 showed a marked increase in CA125 serum, suggesting that it could block the binding between mesothelin and Ca-125. It was demonstrated that MORAb-009 could inhibit cellular adhesion during metastasis in cases of both ovarian carcinomas and mesotheliomas [56,57]. Studies in vivo on animal models demonstrated that these effects were markedly increased in combination with chemotherapy agents such as gemcitabine and Taxol [57] or, in a phase II clinical trial, with other chemotherapeutic substances for cases of mesotheliomas (ClinicalTrials.gov Identifier: NCT00738582) [58]. The reduction in the MPF level in serum, after treatment, demonstrated a correlation with a good prognosis [58]. However, the combination with chemotherapy agents caused adverse events, such as hypersensitivity reactions, neutropenia, and atrial fibrillation [58].

Although most studies (ClinicalTrials.gov Identifiers: NCT01521325, NCT01413451) on ovarian carcinomas focused on the efficacy of monotherapy with MORAb-009, these data suggest that a combination with different chemotherapeutic agents could provide satisfactory results, with prolongated overall survival.

Anti-Mesothelin Antibody Drug Conjugate (BAY-94 9343)

Anti-mesothelin antibody-drug conjugate (BAY-94 9343), known as anetumab ravtansine, is an 
antibody-drug conjugate (ADC) that is a complex consisting of a fully human immunoglobulin G1 antimesothelin monoclonal antibody conjugated to the maytansine derivative tubulin inhibitor DM4 through a reducible disulphide linker (FIG 2C) [59]. BAY-94 9343 has an anti-proliferative activity because, after binding to mesothelin on tumour cells, it is internalized, and the disulphide linker is cleaved, releasing DM4. Subsequently, DM4 binding to tubulin disrupts the microtubule polymerization, causing cell cycle arrest and apoptosis and consequently killing the dividing cells $[60,61]$.

Preclinical studies have shown that anetumab ravtansine was highly cytotoxic in MSLNexpressing mesotheliomas as well as pancreatic, non-small-cell lung and ovarian cancer cell lines [58].

In vivo, anetumab ravtansine had antitumor activity in mesotheliomas as well as pancreatic and ovarian xenograft models [59].

The study of Quanz et al. demonstrated that in ovarian cancer cell lines and patient-derived xenografts, the combination of anetumab ravtansine with pegylated liposomal doxorubicin (PLD) or with carboplatin, copanlisib, or bevacizumab showed an additive anti-proliferative activity both in vitro and in vivo compared with either agent used as a monotherapy [62].

\section{Chimeric Antigen Receptor T cell (CAR T) Therapy}

MSLN has also been regarded as an attractive target for chimeric antigen receptor $\mathrm{T}$ cell (CAR T) therapy because of its abundant expression in tumour cells and a limited expression in normal cells.

CAR $\mathrm{T}$ therapy is a type of treatment in which the $\mathrm{T}$ cells of a patient, obtained by apheresis, are changed in the laboratory by inserting a gene for a special receptor called a chimeric antigen receptor (CAR) into them. CAR T cells can target cell surface antigens without MHC (Major histocompatibility complex) restriction. Thus, CAR T cells can use for broad HLA-diverse allogenic recipients.

The CAR usually is complex with an extra-cellular antigen recognition domain, which corresponds to a single chain variable fragment ( $\mathrm{scFv}$ ) of a specific antibody, a transmembrane domain, anchored at the cell membrane of $\mathrm{T}$ cell and an intra-cellular domain that transmits to $\mathrm{T}$ cell activation signals. To amplify the activation signals in Cars, MSLN can be used in two costimulators domains which allow obtaining major activation in terms of proliferation, cytotoxicity, and, consequently, major anti-tumour efficacy. The major effectiveness of this subtype of CAR, known as 'third-generation MSLN', was proven in many neoplasms and in ovarian carcinoma [63].

In the laboratory, CAR-T cells can be produced using a lentivirus vector, which is integrated into the 
genome of the host $\mathrm{T}$ cell. This method is widely used in phase I studies in advanced solid cancer with MSLN expression [64].

The CAR T cells are grown in the laboratory and then given to the patient by infusion. The CAR T cells are able to bind to the antigens on the cancer cells and kill them. Once attached to the antigens present on the neoplastic cells, the CAR T cells become activated and stimulate the host immunosystem, which in

\section{2}

turn attacks the MSLN-expressing cells [65]. The effectiveness of CAR T therapy has been observed in mouse models of different solid neoplasms, including ovarian carcinomas and mesotheliomas, in which the chimeric receptors recognize human MSLN, and the inflammatory cytokines secreted by the $\mathrm{T}$ cells (including IL-2, IL-6, tumour necrosis factor alpha, and Interferon-y) that produce cytotoxic effects for the cancer cells (FIG 2 D) $[66,67]$.

For high-grade serous ovarian cancer (HGSC), investigating the co-expression of CA125, MSLN and folate receptor alpha (FOLRA) on individual tumour cells and their relationship with tumour-infiltrating $\mathrm{T}$ cells (TIL), Banville et al. provided insights into the design of logic-gated CAR $\mathrm{T}$ cell strategies with a greater number of antigens. They demonstrated that the most promising pairwise combination was CA125 and/or MSLN. Thus, a CAR T cell strategy against CA125 and MSLN would target most tumour cells in most cases. The antigen expression and $\mathrm{T}$ cell infiltration demonstrated that this strategy was effective both in primary and recurrent diseases [68].

However, as observed in treatments for other neoplasms, it must be kept in mind that the immunosuppressive tumour microenvironment of neoplasms plays an important role in response to CAR T therapy in vivo. Many authors have demonstrated that a transmembrane protein named programmed deathligand 1 (PD-L1) has an important role in regulating $\mathrm{T}$ cell response. The binding of this substance to an inhibitor programmed cell death protein 1 (PD-1) or the binding of PD-1 to the immune co-inhibitory receptors lymphocyte activation gene-3 (LAG3) transmit an inhibitory signal, causing a reduction in the proliferation of antigen-specific T-cells, and, consequently, reduction in the infiltration of $\mathrm{T}$ cells into the tumour lesion [69].

For ovarian carcinoma, recent preclinical studies in vivo showed that it is possible to restore the functions of tumour-specific checkpoint blockade in MSLN-directed CAR T cells using different substances [70-72]. 
The side effects of treatment observed during CAR $\mathrm{T}$ therapy are related to excessive immune activation, which causes cytokine release syndrome (CRS) and neurotoxicity. These adverse effects are probably due to non-specific $\mathrm{T}$ cell activation.

The (CRS) is an acute systemic inflammatory disorder characterized by fever and, sometimes, fatal dysfunction of many organs $[73,74]$. Patients with severe CRS symptoms can culminate in delirium, seizures, and encephalopathy caused by high levels of L-6, IFN gamma, and CAR T cells in the cerebrospinal fluid [75].

Compartmental CRS (C-CRS) has been reported in a patient with advanced ovarian cancer treated with mesothelin-targeted CAR T cells characterized by the elevation of IL-6 and accumulation in the pleural fluid [74].

The treatment used against this serious side effect sometimes involves using an anti-IL-6R antibody, tocilizumab [76]. In cases with involvement of the nervous system and unresponsive cases to tocilizumab, corticosteroids were often used $[75,77,78]$, or suicide genes were introduced within T cells to reduce their number and activity (ClinicalTrials.gov Identifiers: NTC0374965).

\section{$\underline{\text { Vaccine }}$}

The cancer vaccine is an immunotherapy that induces a tumour-specific immunoresponse in the host, which is capable of recognizing and eliminating neoplastic cells. The ability of $\mathrm{T}$ cells to recognize antigens present on neoplastic cells and to produce an immune response capable of destroying them has long been known.

In fact, as early as 1891, Dr William Coley observed the regression of a sarcoma by injecting inactivated Streptococcus pyogenes and Serratia marcescens into the neoplasm [79].

Currently, Listeria monocytogenes, a Gram-positive bacterium, can be used as a vector for this type of immunotherapy for MSLN-positive cancers. In humans, this bacterium causes infections with gastroenteritis, meningitis, and encephalitis, but generally, the human immune system is capable of controlling the disease $[80,81]$.

The CRS-207 vaccine uses attenuated Listeria monocytogenes (Lm) (Lm $\Delta$ actA/ $\Delta$ inlB) that are engineered to express human MSLN and can be used to treat MSLN-positive neoplasms (FIG 2E) [82]. 
The methods used to attenuate the virulence of Lm are mostly based on the deletion of certain genes that allow for sufficient infectivity and antigen production but have the potential for severe infection. Therefore, this treatment should be used with caution for patients who have immunodeficiency [83].

Treatment with CRS-207 with Listeria-expressing human MSLN allows for stimulating the immune system with a robust response against neoplastic cells by different mechanisms. After the fusion with a lysosome in the cytoplasm of an antigen-presenting cell, Lm can be killed; the secretions of its antigens into the cytosol as well as prior to the degradation in the phagosome can be loaded onto (Major

\section{4}

Histocompatibility Complex) MHC I and MCH II, causing the activation of potent CD 4 helper lymphocytes and CD8 cytotoxic lymphocytes.

In addition, during its entry in the antigen-presenting cell, Lm, by Toll-like receptors, can activate pro-inflammatory genes, which can amplify, by inflammatory cytokines, the response against neoplastic cells [84].

After phase I testing, the safety of CRS-207 was demonstrated in patients with ovarian cancers as well as pancreatic, mesothelioma, and lung carcinoma (ClinicalTrials.gov identifier NCT00585845) and in platinum-resistant ovarian, fallopian or peritoneal serous carcinomas (ClinicalTrials.gov identifier NCT02575807).

\section{CONCLUSIONS}

In conclusion, a typical expressing pattern of MSLN in normal and cancer tissues makes it a promising target for diagnosis and therapeutic applications. Although many clinical trials regarding MSLNtargeting therapies in ovarian carcinomas are underway, further studies are necessary to establish the effects on the health of patients and behavioural outcomes. 


\section{$\underline{\text { Author Contributions }}$}

Conceptualization, G.G. and E.F.; methodology, G.G. and A.T.; formal analysis, G.G. and E.F.; writingoriginal draft preparation, G.G.and E.F:; writing-review and editing, G.G. and A.T.

All authors have read and agreed to the published version of the manuscript.

\section{Funding}

Not applicable

\section{$\underline{\text { Institutional Review Board Statement }}$}

Not applicable.

\section{Informed Consent Statement}

Not applicable.

\section{$\underline{\text { Data Availability Statement }}$}

Not applicable.

\section{Conflicts of Interest}

The authors declare no conflict of interest

\section{Figure Legend}

FIG 1: Examples of high-grade serous carcinoma, with diffuse mesothelin immunoreactivity. (a: score 4+, x100; b: score 3+, x100).

FIG 2: Schematic and simplified representation of the main therapeutic strategies, using mesothelin as a target. 
16

\section{Rereferences}

1) Chang, K.; Pastan, I. Molecular cloning of mesothelin, a differentiation antigen present on mesothelium, mesotheliomas, and ovarian cancers. Proc. Natl. Acad. Sci. US A 1996, 93, 136-140

2) Kojima, T.; Oh-eda, M.; Hattori, K.; Taniguchi, Y.; Tamura, M.; Ochi, N.; Yamaguchi, N. Molecular cloning and expression of megakaryocyte potentiating factor cDNA. J. Biol. Chem. 1995, 270, 21984-21990. DOI: 10.1074/jbc.270.37.21984

3) Bera, T.K.; Pastan, I. Mesothelin is not required for normal mouse development or reproduction. Mol. Cell. Biol. 2000, 20, 2902-2906. DOI: 10.1128/MCB.20.8.2902-2906.2000

4) Tang, Z.; Qian, M.; Ho, M. The role of mesothelin in tumor progression and targeted therapy. Anticancer Agents Med. Chem. 2013, 13, 276-280. DOI: 10.2174/1871520611313020014

5) Rump, A.; Morikawa, Y.; Tanaka, M.; Minami, S.; Umesaki, N.; Takeuchi, M.; Miyajima, A. Binding of ovarian cancer antigen CA125/MUC16 to mesothelin mediates cell adhesion. J. Biol. Chem. 2004, 279, 9190-9198. DOI: 10.1074/jbc.M312372200

6) Gubbels, J.A.; Belisle, J.; Onda, M.; Rancourt, C.; Migneault, M.; Ho, M.; Bera, T.; K.; Connor, J.; Sathyanarayana, B.K.; Lee, B.; et al. Mesothelin-MUC16 binding is a high affinity, N-glycan dependent interaction that facilitates peritoneal metastasis of ovarian tumors. Mol. Cancer. 2006, 5, 50. DOI: $10.1186 / 1476-4598-5-50$.

7) Cheng, W.F.; Hung, C.F.; Chai, C.Y.; Chen, C.A.; Lee, C.N; Su, Y.N.; Tseng, W.Y.; Hsieh, C.Y.; Shih, IeM.; Wang, T.L. et al. Generation and characterization of an ascitogenic mesothelinexpressing tumor model. Cancer. 2007, 110, 420-431. DOI: 10.1002/cncr.22781

8) Chang, C. L.; Wu, T.C.; Hung, C.F. Control of human mesothelin-expressing tumors by DNA vaccines. Gene Ther. 2007, 14, 1189-1198. DOI: 10.1038/sj.gt.3302974

9) Moher, D.; Liberati, A.; Tetzlaff, J.; Altman, D.G.; PRISMA Group. Preferred reporting items for systematic reviews and meta-analyses: The PRISMA statement. PLoS Med. 2009, 62, 1006-1012

10) American Cancer Society. Cancer Facts \& Figures 2012.Atlanta, Ga, USA: American Cancer Society; 2012

11) Cristaudo, A.; Foddis, R.; Vivaldi, A.; Guglielmi, G.; Dipalma, N.; Filiberti, R.; Neri, M.; Ceppi, M.; Paganuzzi, M.; Ivaldi, G.P. et al. Clinical significance of sera mesothelin in patients with mesothelioma and lung cancer. Clin. Cancer Res. 2007, 13, 5076-5081. DOI: 10.1158/10780432.CCR-07-0629.

12) Berruti, A.; Tampellini, M.; Torta, M.; Buniva, T.; Gorzegno, G.; Dogliotti L. Prognostic value in predicting overall survival of two mucinous markers: CA 15-3 and CA 125 in breast cancer patients at first relapse of disease. Eur. J. Cancer 1994, 30, 2082-2084. DOI: 10.1016/0959-8049(94)00356a

13) Norum, L.F.; Erikstein, B.; Nustad, K. Elevated CA125 in breast cancer-a sign of advanced disease. Tumour Biol. 2000. 22, 223-228

14) Hedman, M.; Arnberg, H.; Wernlund, J.; Riska, H.; Brodin, O. Tissue polypeptide antigen (TPA), hyaluronan and CA 125 as sera markers in malignant mesothelioma. Anticancer Res. 2003. 23, 531536 
15) Bairey, O.; Blickstein, D.; Stark, P.; Prokocimer, M.; Nativ, H.M.; Kirgner, I.; Shaklai, M. Serum CA 125 as a prognostic factor in non-Hodgkin's lymphoma. Leuk. Lymphoma. 2003, 44, 1733-1738. DOI: $10.1080 / 1042819031000104079$.

16) Burney, I.A.; Siddiqui, T.; Siddiqui, I. Serum CA 125 is of clinical value in the staging and follow-up of patients with non- Hodgkin's lymphoma: correlation with tumor parameters and disease activity. Cancer. 1999, $\quad 85, \quad 755-756 . \quad$ DOI: $\quad 10.1002 /($ sici)1097-0142(19990201)85:3<755::aidcncr27>3.0.co;2-o

17) Zidan, J.; Hussein, O.; Basher, W.; Zohar, S. Serum CA125: a tumor marker for monitoring response to treatment and follow-up in patients with non-Hodgkin's lymphoma. Oncologist 2004, 9, 417-421. DOI: 10.1634/theoncologist.9-4-417.

18) Yamamoto, M.; Baba, H.; Toh, Y.; Okamura, T.; Maehara, Y. Peritoneal lavage CEA/CA125 is a prognostic factor for gastric cancer patients. J. Cancer Res. Clin. Oncol. 2007, 33, 471-476. DOI: 10.1007/s00432-006-0189-2.

19) Jacobs, I.; Bast, R.C. Jr. The CA 125 tumour-associated antigen: a review of the literature. Hum. Reprod. 1989, 4:1-12. DOI: 10.1093/oxfordjournals.humrep.a136832

20) Zurawski, V.R.; Knapp, R.C.; Einhorn, N.; Kenemans, P.; Mortel, R.; Ohmi, K.; Bast, R.C.Jr.; Ritts, R.E. Jr; Malkasian, G. An initial analysis of pre-operative serum CA125 levels in patients with early stage ovarian carcinoma. Gynecol. Oncol. 1998, 30,7-14. DOI: 10.1016/0090-8258(88)90039-x

21) Einhorn, N. Ovarian cancer: early diagnosis and screening. Hematol. Oncol. Clin. North. Am. 1992, $6,843-850$

22) Ordóñez, N.G. Application of mesothelin immunostaining in tumor diagnosis. Am. J. Surg. Pathol. 2003, 27,1418-1428. DOI: 10.1097/00000478-200311000-00003.

23) Scholler, N.; Fu N.; Yang, Y.; Ye, Z.; Goodman, G.E.; Hellström, K.E.; Hellström, I. Soluble member(s) of the mesothelin/megakaryocyte potentiating factor family are detectable in sera from patients with ovarian carcinoma. Proc. Natl. Acad. Sci. US A. 1999, 96, 11531-11536. DOI 10.1073/pnas.96.20.11531

24) Wu, X.; Li, D.; Liu, L.; Liu, B.; Liang, H.; Yang, B. Serum soluble mesothelin-related peptide (SMRP): a potential diagnostic and monitoring marker for epithelial ovarian cancer. Arch. Gynecol. Obstet. 2014, 289, 1309-1314. DOI: 10.1007/s00404-013-3128-x

25) Okła, K.; Surówka, J.; Frąszczak, K.; Czerwonka, A.; Kaławaj, K.; Wawruszak, A.; Kotarski, J.; Wertel, I. Assessment of the clinicopathological relevance of mesothelin level in plasma, peritoneal fluid, and tumor tissue of epithelial ovarian cancer patients. Tumour Biol. 2018, 40, 1-15. DOI: $10.1177 / 1010428318804937$

26) Huang, C.Y.; Cheng, W.F.; Lee, C.N.; Su, Y.N.; Chien, S.C.; Tzeng, Y.L.; Hsieh, C.Y.; Chen, C.A. Serum mesothelin in epithelial ovarian carcinoma: a new screening marker and prognostic factor. Anticancer Res. 2006, 26, 4721-4728.

27) Badgwell, D.; Lu, Z.; Cole, L.; Fritsche, H.; Atkinson, E.N.; Somers, E.; Allard, J.; Moore, R.G.; Lu, K.H.; Bast, R.C. Jr. Urinary mesothelin provides greater sensitivity for early stage ovarian cancer than serum mesothelin, urinary hCG free beta subunit and urinary hCG beta core fragment. Gynecol. Oncol. 2007, 106, 490-497. DOI: 10.1016/j.ygyno.2007.04.022.

28) Hellstrom, I.; Hellstrom, K.E. Two novel biomarkers, mesothelin and HE4, for diagnosis of ovarian 
carcinoma. Expert Opin. Med. Diagn. 2011, 5, 227-240. DOI: 10.1517/17530059.2011.559459

29) Sandow, J.J.; Rainczuk, A.; Infusini, G.; Makanji, M.; Bilandzic, M.; Wilson A.L.; Fairweather, N.; Stanton P.G.; Garama, D.; Gough, D. et al. Discovery and validation of novel protein biomarkers in ovarian cancer patient urine. Proteomics Clin. Appl. 2018, 12, e1700135. DOI: 10.1002/prca.201700135

30) Hollevoet, K.; Speeckaert, M.M.; Decavele, A.S.; Vanholder, R.; van Meerbeeck, J.P.; Delanghe, J.R. Mesothelin levels in urine are affected by glomerular leakage and tubular reabsorption. Clin. Lung Cancer. 2012, 13, 470-474. DOI: 10.1016/j.cllc.2011.12.004

31) Prantner, A.M.; Turini, M.; Kerfelec, B.; Joshi, S.; Baty, D.; Chames P.; Scholler, N. Anti-mesothelin nanobodies for both conventional and nanoparticle-based biomedical applications. J. Biomed. Nanotechnol. 2015, 11, 1201-1212. DOI: 10.1166/jbn.2015.2063

32) Prantner A.M.; Yin, C.; Kamat, K.; Sharma, K.; Lowenthal, A.C.; Madrid, P.B.; Scholler, N. Molecular imaging of mesothelin-expressing ovarian cancer with a human and mouse cross reactive nanobody. Mol. Pharm. 2018, 15, 1403-1411. DOI: 10.1021/acs.molpharmaceut.7b00789

33) Scales, S.J.; Gupta, N.; Pacheco, G.; Firestein, R.; French, D.M.; Koeppen, H.; Rangell, L.; BarryHamilton V.; Luis E.; Chuh J. et al. An antimesothelin-monomethyl auristatin e conjugate with potent antitumor activity in ovarian, pancreatic, and mesothelioma models. Mol. Cancer Ther. 2014, 13, 2630-2640. DOI: 10.1158/1535-7163.MCT-14-0487-T

34) Lamberts, L.E.; Menke-van der Houven van Oordt, C.W.; ter Weele, E.J.; Bensch, F.; Smeenk, M.M.; Voortman, J.; Hoekstra, O.S.; Williams, S.P.; Fine, B.M.; Maslyar, D. et al. ImmunoPET with anti-mesothelin antibody in patients with pancreatic and ovarian cancer before anti-mesothelin antibody-drug conjugate treatment. Clin. Cancer Res. 2016, 22, 1642-1652. DOI: 10.1158/10780432.CCR-15-1272

35) Terwisscha van Scheltinga, A.G.; Ogasawara, A.; Pacheco, G.; Vanderbilt, A.N.; Tinianow, J.N.; Gupta, N.; Li, D.; Firestein, R.; Marik, J.; Scales S.J.et al. Preclinical efficacy of an antibody-drug conjugate targeting mesothelin correlates with quantitative 89Zr-ImmunoPET. Mol. Cancer Ther. 2017, 16:134-142. DOI: 10.1158/1535-7163.MCT-16

36) Williams, S.P. Preclinical Efficacy of an Antibody-Drug Conjugate Targeting Mesothelin Correlates with Quantitative 89Zr-ImmunoPET. Mol. Cancer Ther. 2017, 16, 134-142. DOI: 10.1158/15357163.MCT-16-0449

37) Duan, D.; Li, S.-L.; Zhu, Y.-Q.; Zhang, T.; Lei, C.-M.; Cheng, X.- H. Radioimmunoimaging with Mixed Monoclonal Antibodies of Nude Mice Bearing Human Lung Adenocarcinoma Xenografts. Asian Pac. J. Cancer Prev. 2012, 13, 4255-4261. DOI: 10.7314/apjcp.2012.13.9.4255

38) Kanner, W.A.; Galgano, M.T.; Stoler, M.H.; Mills, S.E.; Atkins, K.A. Distinguishing breast carcinoma from Müllerian serous carcinoma with mammaglobin and mesothelin. Int. J. Gynecol. Pathol. 2008, 27, 491-495.DOI: 10.1097/PGP.0b013e31817d5340

39) Weidemann, S.; Gagelmann, P.; Gorbokon, N.; Lennartz, M.; Menz, A.; Luebke, A.M.; Kluth, M.; Hube-Magg, C.; Blessin, N.C.; Fraune, C.; et al. Mesothelin Expression in Human Tumors: A Tissue $\begin{array}{llllll}\text { Microarray Study on 12,679 Tumors. Biomedicines 2021, } & 397 .\end{array}$ DOI:10.3390/biomedicines9040397

40) Chang, K.; Pastan, I.; Willingham, M.C. Isolation and characterization of a monoclonal antibody, K1, reactive with ovarian cancers and normal mesothelium. Int. J. Cancer 1992, 50, 373-381. DOI: 


\section{$10.1002 /$ ijc. 2910500308}

41) Yildiz, Y.; Kabadayi, G.; Yigit, S.; Kucukzeybek, Y.; Alacacioglu, A.; Varol, U.; Taskaynatan, H.; Salman, T.; Oflazoglu, U.; Akyol, M.; Tarhan, M.O. High expression of mesothelin in advanced serous ovarian cancer is associated with poor prognosis. J BUON. 2019, 24, 1549-1554.

42) Cheng, W.F.; Huang, C.Y.; Chang, M.C.; Hu, Y.H.; Chiang, Y.C.; Chen, Y.L.; Hsieh, C.Y.; Chen, C.A. High mesothelin correlates with chemoresistance and poor survival in epithelial ovarian carcinoma. Br. J. Cancer. 2009,100, 1144-1153. DOI: 10.1038/sj.bjc.6604964.

43) Yen, M.J.; Hsu, C.Y.; Mao, T.L.; Wu, T.C.; Roden, R.; Wang, T.L.; Shih, IeM. Diffuse mesothelin expression correlates with prolonged patient survival in ovarian serous carcinoma. Clin. Cancer Res. 2006, 12, 827-831. DOI: 10.1158/1078-0432.CCR-05-1397

44) Thomas, A.; Chen, Y.; Steinberg, S.M.; Luo, J.; Pack, S.; Raffeld, M.; Abdullaev, Z.; Alewine, C.; Rajan, A.; Giaccone, G. et al. High mesothelin expression in advanced lung adenocarcinoma is associated with KRAS mutations and a poor prognosis. Oncotarget 2015, 6, 11694-703. DOI: 10.18632/oncotarget.3429

45) Einama, T.; Kamachi, H.; Nishihara, H.; Homma, S.; Kanno, H.; Takahashi, K.; Sasaki, A.; Tahara, M.; Okada, K.; Muraoka, S. et al. Co-expression of mesothelin and CA125 correlates with unfavorable patient outcome in pancreatic ductal adenocarcinoma. Pancreas 2011, 40, 1276 1282. DOI: 10.1097/MPA.0b013e318221bed8

46) Magalhaes, I.; Fernebro, J.; Abd Own, S.; Glaessgen,, D.; Corvigno, S.; Remberger, M.; Mattsson, J.; Dahlstrand, H. Mesothelin Expression in Patients with High-Grade Serous Ovarian Cancer Does Not Predict Clinical Outcome But Correlates with CD11c+ Expression in Tumor. Adv. Ther. 2020, 37 , 5023-5031. DOI: 10.1007/s12325-020-01520-w.

47) Narod, S. Can advanced-stage ovarian cancer be cured? Nat. Rev. Clin. Oncol. 2016, 13, $255-261$. DOI: $10.1038 /$ nrclinonc. 2015.224

48) Ruan, G.; Ye, L.; Liu, G.; An, J.; Sehouli, J.; Sun, P. The role of bevacizumab in targeted vascular endothelial growth factor therapy for epithelial ovarian cancer: an updated systematic review and meta-analysis. Onco Targets Ther. 2018,11, 521-528. DOI: 10.2147/OTT.S155581.

49) Gourley, C.; Balmaña, J.; Ledermann, J.A.; Serra, V.; Dent, R.; Loibl, S.; Pujade-Lauraine, E.; Boulton, S.J. Moving from poly (ADP-Ribose) polymerase inhibition to targeting DNA repair and DNA damage response in cancer therapy. J. Clin. Oncol. 2019, 37, 2257-2269. DOI: 10.1200/JCO.18.02050.

50) Pastan, I.; Hassan, R.; FitzGerald, D.J.; Kreitman, R.J. Immunotoxin therapy of cancer. Nat. Rev. Cancer 2006, 6:559-565. DOI: 10.1038/nrc1891

51) Hassan, R.; Lerner, M.R.; Benbrook, D.; Lightfoot, S.A.; Brackett, D.J.; Wang, Q.C.; Pastan, I. Antitumor activity of $\mathrm{SS}(\mathrm{dsFv}) \mathrm{PE} 38$ and $\mathrm{SS} 1(\mathrm{dsFv}) \mathrm{PE} 38$, recombinant antimesothelin immunotoxins against human gynecologic cancers grown in organotypic culture in vitro. Clin. Cancer Res. 2002, 8, 3520-3526.

52) Hassan, R.; Bullock, S.; Premkumar, A.; Kreitman, R.J.; Kindler, H.; Willingham, M.C.; Pastan, I. Phase I study of SS1P, a recombinant anti-mesothelin immunotoxin givens as bolus I.V. infusion to patients with mesothelin-expressing mesothelioma, ovarian, and pancreatic cancers. Clin. Cancer Res. 2007, 13, 5144-5149. DOI: 10.1158/1078-0432.CCR-07-0869 
53) Hassan, R.; Sharon, E.; Thomas, A.; Zhang, J.; Ling, A.; Miettinen, M.; Kreitman, R.J.; Steinberg S.M.; Hollevoet, K.; Pastan, I. Phase 1 study of the antimesothelin immunotoxin SS1P in combination with pemetrexed and cisplatin for front-line therapy of pleural mesothelioma and correlation of tumor response with serum mesothelin, megakaryocyte potentiating factor, and cancer antigen 125. Cancer 2014, 120, 3311-3319. DOI: 10.1002/cncr.28875

54) Hassan, R., Miller, A.C., Sharon, E., Thomas, A., Reynolds, J.C., Ling, A., Kreitman, R.J., Miettinen, M.M., Steinberg, S.M., Fowler, D.H., et al. Major cancer regressions in mesothelioma after treatment with an anti-mesothelin immunotoxin and immune suppression. Sci Transl Med. 2013, 23, 208ra147. DOI: 10.1126/scitranslmed.3006941.

55) Hassan, R.; Ebel, W.; Routhier, E.L.; Patel, R.;Kline, J.B.; Zhang, J. Preclinical evaluation of MORAb-009, a chimeric antibody targeting tumor-associated mesothelin. Cancer Immun. 2007, 7, 20.

56) Hassan, R.; Schweizer, C.; Lu, K.F.; Schuler, B.; Remaley, A.T.; Weil, SC. Inhibition of mesothelinCA-125 interaction in patients with mesothelioma by the anti-mesothelin monoclonal antibody MORAb-009: implications for cancer therapy. Lung Cancer. 2010, 68, 455-459. DOI: 10.1016/j.lungcan.2009.07.016

57) Hassan, R.; Cohen, S.J.; Phillips, M.; Pastan, I.; Sharon, E.; Kelly, R.J.; Schweizer, C.; Weil, S.; Laheru, D. Phase I clinical trial of the chimeric anti-mesothelin monoclonal antibody MORAb-009 in patients with mesothelin expressing cancers. Clin. Cancer Res. 2010, 16, 6132-6138. DOI: 10.1158/1078-0432.CCR-10-2275

58) Hassan, R.; Kindler, H.L.; Jahan, T.; Bazhenova, L.; Reck, M.; Thomas, A.; Pastan, I.; Parno, J.; O'Shannessy, D.J.;;Fatato, P.; et al. Phase II clinical trial of amatuximab, a chimeric antimesothelin antibody with pemetrexed and cisplatin in advanced unresectable pleural mesothelioma. Clin. Cancer Res. 2014, 20, 5927-5936. DOI: 10.1158/1078-0432.CCR-14-0804

59) Golfier, S.; Kopitz, C.; Kahnert, A.; Heisler, I.; Schatz, C.A.; Stelte-Ludwig, B.; Mayer-Bartschmid, A.; Unterschemmann, K.; Bruder, S.; Linden, L.; et al. Anetumab ravtansine: a novel mesothelintargeting antibody-drug conjugate cures tumors with heterogeneous target expression favored by bystander effect. Mol. Cancer Ther. 2014, 13,1537-1548. DOI: 10.1158/1535-7163.MCT-13-0926

60) Chen, H.; Lin, Z.; Arnst, K.E.; Miller, D.D.; Li, W. Tubulin Inhibitor-Based Antibody-Drug Conjugates for Cancer Therapy. Molecules. 2017, 22, 1281. DOI: 10.3390/molecules22081281.

61) Chalouni, C.; Doll, S. Fate of Antibody-Drug Conjugates in Cancer Cells. J Exp Clin Cancer Res. 2018, 37, 20. DOI: 10.1186/s13046-017-0667-1.

62) Quanz, M.; Hagemann, U.B.; Zitzmann-Kolbe, S.; Stelte-Ludwig, B.; Golfier, S.; Elbi, C.; Mumberg, D.; Ziegelbauer, K.; Schatz, C.A. Anetumab ravtansine inhibits tumor growth and shows additive effect in combination with targeted agents and chemotherapy in mesothelin-expression human ovarian cancer models. Oncotarget. 2018, 9, 34103-34121. DOI: 10.18632/oncotarget.26135

63) Hung, C.F, Xu, X., Li, L., Ma, Y., Jin, Q., Viley, A., Allen, C., Natarajan, P., Shivakumar, R., Peshwa, M.V., Emens, L.A. Development of Anti-Human Mesothelin-Targeted Chimeric Antigen Receptor Messenger RNA-Transfected Peripheral Blood Lymphocytes for Ovarian Cancer Therapy. Hum Gene Ther. 2018, 29, 614-625. DOI: 10.1089/hum.2017.080.

64) Haas, A.R., Tanyi, J.L., O'Hara M.H., Gladney, W.L., Lacey S.F., Torigian, D.A., Soulen, M.C., Tian, 
L., McGarvey, M., Nelson, A.M., et al. Phase I Study of Lentiviral-Transduced Chimeric Antigen 21

Receptor-Modified T Cells Recognizing Mesothelin in Advanced Solid Cancers. Mol Ther. 2019, 27, 1919-1929. DOI: 10.1016/j.ymthe.2019.07.015.

65) Beatty, G.L.; Haas, A.R.; Maus, M.V.; Torigian, D.A.; Soulen M.C.; Plesa, G.; Chew, A.; Zhao, Y.; Levine, B.L.; Albelda, S.M.; et al. Mesothelin-specific chimeric antigen receptor mRNA-engineered $\mathrm{T}$ cells induce anti-tumor activity in solid malignancies. Cancer Immunol. Res. 2014, 2, 112-120. DOI: 10.1158/2326-6066.CIR-13-0170.

66) Carpenito, C.; Milone, M.C.; Hassan, R.; Simonet, J.C.; Lakhal, M.; Suhoski, M.M.; Varela-Rohena, A.; Haines, K.M.; Heitjan, D.F.; Albelda, S.M.; et al. Control of large, established tumor xenografts with genetically retargeted human T cells containing CD28 and CD137 domains. Proc. Natl. Acad. Sci. US A. 2009, 106, 3360-3365. DOI: 10.1073/pnas.0813101106

67) Sandaltzopoulos, R.; Scholler, N.; Powell, D.J.; Jr. Redirected antitumor activity of primary human lymphocytes transduced with a fully human anti-mesothelin chimeric receptor. Mol. Ther. 2012, 20, 633-643. DOI: 10.1038/mt.2011.256.

68) Banville, A.C.; Wouters, M.C.A.; Oberg, A.L.; Goergen, K.M.; Maurer, M.J.; Milne, K.; Ashkani, J.; Field, E.; Ghesquiere, C.; Jones, S.J.M.; et al. Co-expression patterns of chimeric antigen receptor (CAR)-T cell target antigens in primary and recurrent ovarian cancer. Gynecol Oncol. 2021, 160, 520-529. DOI: 10.1016/j.ygyno.2020.12.005.

69) Li, J., Li, W., Huang, K., Zhang, Y., Kupfer, G., Zhao, Q. Chimeric antigen receptor T cell (CAR-T) immunotherapy for solid tumors: lessons learned and strategies for moving forward. J Hematol Oncol. 2018, 11, :22. DOI: 10.1186/s13045-018-0568-6.

70) Huang, R.Y., Eppolito, C., Lele, S., Shrikant, P., Matsuzaki, J., Odunsi, K. LAG3 and PD1 coinhibitory molecules collaborate to limit CD8+ T cell signaling and dampen antitumor immunity in a murine ovarian cancer model. Oncotarget 2015, 6, 27359-27377.

71) Matsuzaki, J., Gnjatic, S., Mhawech-Fauceglia, P., Beck, A., Miller, A., Tsuji, T., Eppolito C, Qian F, Lele S, Shrikant P, et al. Tumor-infiltrating NY-ESO-1-specific CD8+ T cells are negatively regulated by LAG-3 and PD-1 in human ovarian cancer. Proc Natl Acad Sci U S A 2010, 107, 78757880

72) Schoutrop, E., El-Serafi, I, Poiret T., Zhao, Y., Gultekin, O., He, R., Moyano-Galceran, L., Carlson, J.W., Lehti, K., Hassan, M., Magalhaes, I., Mattsson, J. Mesothelin-Specific CAR T Cells Target Ovarian Cancer. Cancer Res. 2021, 81, 3022-3035. DOI: 10.1158/0008-5472.CAN-20-2701.

73) Frey, N., Porter, D. Cytokine Release Syndrome with Chimeric Antigen Receptor T Cell Therapy. Biol Blood Marrow Transplant. 2019, 25, e123-e127. DOI: 10.1016/j.bbmt.2018.12.756.

74) Tanyi, J.L., Stashwick, C., Plesa, G., Morgan, M.A., Porter, D., Maus, M.V., June, C.H. Possible Compartmental Cytokine Release Syndrome in a Patient With Recurrent Ovarian Cancer After Treatment With Mesothelin-targeted CAR-T Cells. J Immunother. 2017, 40, 104-107. DOI: 10.1097/CJI.0000000000000160.

75) Hu, Y., Sun, J., Wu, Z., Yu, J., Cui, Q., Pu, C., Liang, B., Luo, Y., Shi, J., Jin, A., et al. Predominant cerebral cytokine release syndrome in CD19-directed chimeric antigen receptor-modified $\mathrm{T}$ cell therapy. J Hematol Oncol. 2016, 9, 70. DOI: 10.1186/s13045-016-0299-5. 
76) Maude, S.L., Laetsch, T.W., Buechner, J., Rives, S., Boyer, M., Bittencourt, H., et al. Tisagenlecleucel in children and young adults with B-cell lymphoblastic leukemia. $N$ Engl J Med. 2018, 378, 439-448. DOI: 10.1056/NEJMoa1709866

77) Neelapu, S.S., Locke, F.L., Bartlett, N.L., Lekakis, L.J., Miklos, D.B., Jacobson, C.A., Braunschweig, I., Oluwole OO, Siddiqi T, Lin Y, Timmerman JM, et al. Axicabtagene Ciloleucel CAR T-Cell Therapy in Refractory Large B-Cell Lymphoma. $N$ Engl J Med. 2017, 377, 2531-2544. DOI: 10.1056/NEJMoa1707447.

78) Davila, M.L., Riviere, I., Wang, X., Bartido, S., Park, J., Curran, K., Chung, S.S., Stefanski, J., Borquez-Ojeda, O., et al. Efficacy and toxicity management of 19-28z CAR T cell therapy in B cell acute lymphoblastic leukemia. Sci Transl Med. 2014, 6, 224ra25. DOI: 10.1126/scitranslmed.3008226

79) McCarthy, E.F. The toxins of William, B. Coley and the treatment of bone and soft-tissue sarcomas. Iowa Orthop. J. 2006, 26, 154-158.

80) Radoshevich, L., Cossart, P. Listeria monocytogenes: towards a complete picture of its physiology and pathogenesis. Nat Rev Microbiol. 2018, 16, 32-46. DOI: 10.1038/nrmicro.2017.126.

81) Oladejo, M., Paterson, Y., Wood, L.M. Clinical Experience and Recent Advances in the Development of Listeria-Based Tumor Immunotherapies. Front Immunol. 2021, 12, 642316. DOI: 10.3389/fimmu.2021.642316.

82) Le, D.T., Brockstedt, D.G., Nir-Paz, R., Hampl, J., Mathur, S., Nemunaitis, J., Sterman, D.H., Hassan, R., Lutz, E., Moyer, B., et al. A live-attenuated Listeria vaccine (ANZ-100) and a liveattenuated Listeria vaccine expressing mesothelin (CRS-207) for advanced cancers: phase I studies of safety and immune induction. Clin Cancer Res. 2012, 18, 858-868. DOI: 10.1158/10780432.CCR-11-2121.

83) Golub, S.H., O'Connell, T.X., Morton, D.L. Correlation of in vivo and in vitro assays of immunocompetence in cancer patients. Cancer Res. 1974, 34, 1833-1837.

84) Flickinger, J.C. Jr, Rodeck, U, Snook, A.E. Listeria monocytogenes as a Vector for Cancer Immunotherapy: Current Understanding and Progress. Vaccines (Basel). 2018, 6, 48. DOI: 10.3390/vaccines6030048. 